\title{
La no violencia de género en secundaria a través de la educación visual y plástica
}

\author{
Roger Espinosa, Francisca \\ Institut de Flix (Tarragona), froger@iesflix.cat \\ Universitat Politècnica de València, fraroes@alumni.upv.es
}

\begin{abstract}
Resumen
Todo individuo, como ser racional, autónomo y a la vez social, siente la necesidad de recluirse en su interior para reflexionar acerca de sus sentimientos, pero, a la vez, necesita compartir sus emociones con los demás.

A través de la docencia, en la materia de educación visual y plástica (EVP) que forma parte del currículo de la educación secundaria obligatoria (ESO), se adopta como hilo conductor de los trabajos a desarrollar a lo largo de un curso lectivo, el tema de la "No violencia de género".

El objetivo de este estudio es dar cuenta sucinta de una serie de actividades pedagógicas orientadas a que el alumnado delibere sobre este tema general y sobre cada propuesta, y que represente su pensamiento a través de los diferentes lenguajes artísticos que conforman el contenido curricular de la etapa.
\end{abstract}

Finalmente, el resultado de los trabajos se expone en las dependencias del instituto y en su espacio virtual, a la vez que, se difunde más allá de los límites del centro por los medios de comunicación convencionales y por el uso de las nuevas tecnologías. De este modo, el alumnado participa en el debate social, muestra su mirada, transmite su preocupación y refleja su postura.

Palabras clave: Educación, sentimiento, emoción, género, no violencia.

\section{Introducción}

La presente experiencia se pone en práctica en el instituto de Flix, un centro público de secundaria situado en un municipio del mismo nombre y con 3.408 habitantes, según datos del Instituto Nacional de Estadística para 2019. Flix se localiza en la comarca de Ribera d'Ebre, Tarragona, y su instituto acoge alumnado procedente del mismo municipio y de sus 
circundantes: La Torre, Ribaro-roja, Ascó y Vinebre. En él se imparte la ESO, el bachiller científico y el humanístico, así como diversos ciclos formativos de grado medio y superior. Pero la investigación se centra en la primera de esas etapas educativas, la ESO, donde la edad del alumnado está comprendida entre los 12 y los 16 años.

Según diversos estudios, en esta franja de edad, se produce el salto del pensamiento concreto, desarrollado en la infancia, y se experimenta con el pensamiento abstracto, es decir, son capaces de plantear hipótesis, de razonar y de pensar sobre nuevas o diferentes posibilidades, luego su aprendizaje no es solo literal. Se inician en el aprendizaje significativo (Ausubel, Novak y Hanesian, 1978), conectan sus conocimientos y muestran sus intereses, así que el trabajo de acompañamiento es primordial para, además, impulsar su aprendizaje funcional y práctico. Se debe estimular su memoria sensorial y su habilidad selectiva, activar su memoria operativa y organizativa, y reforzar su capacidad de almacenamiento en la memoria a largo plazo para que finalmente puedan integrarlo y transferirlo a nuevas situaciones. La actividad mediadora del docente les deberá conducir, en ese proceso de construcción identitaria y social, a través de ejemplos y modelos de calidad que fortalezcan su aprendizaje positivo y reflexivo sin perder de vista la singularidad individual de cada persona y su diversidad funcional, puesto que se trabaja con seres humanos jóvenes que conformarán la sociedad del futuro.

Dentro de la materia de educación visual y plástica, el currículo de la ESO introduce aspectos que pueden tratarse de manera transversal con otras asignaturas y, así, crear un proyecto educativo global de aprendizaje, luego con esa vocación se afronta la idea del presente trabajo.

\section{Objetivo}

El objetivo general del estudio es acompañar al alumnado adolescente en su reflexión contra la violencia de género, mientras que el objetivo específico versa sobre su capacidad expresiva para representar su percepción del tema a través de técnicas gráfico-plásticas y, posteriormente, exponerlo, publicarlo y difundirlo en los medios a través de los sistemas convencionales de comunicación y de las redes sociales. 


\section{Marco teórico}

En el mundo occidental y, concretamente, en España, la educación es un principio fundamental reconocido a toda persona de acuerdo con la Declaración Universal de los Derechos Humanos (1948) y la Constitución (1978), pues contribuye a erigir su dignidad y a desarrollar su personalidad. Por tanto, la labor de las docentes y los docentes ocupa una posición clave en el desempeño de su función como agentes sociales y educadoras/educadores del desarrollo individual y colectivo del alumnado. En definitiva, sobre estas miradas, los gobiernos y los modelos educativos han desarrollado estrategias y protocolos de actuación, pero la sociedad, las familias y el equipo docente deberán guiar a las y los adolescentes en la construcción de su narrativa biográfica presente y futura.

Así pues, en este sentido, para tratar el tema de la no violencia de género desde el ámbito artístico, se decide dar un giro al enfoque a través del refuerzo positivo de la figura femenina y, de este modo, siguiendo las directrices que establece el Decreto 187/2015 de la Generalitat de Catalunya, se busca el fortalecimiento de la personalidad del alumnado de secundaria a través del respeto hacia la diversidad, de la cultura de la paz en la resolución de conflictos y de los valores éticos en repulsa de los estereotipos.

De otro lado, para vincular lo que sucede dentro de las aulas con la vida de su ciudadanía local, se hace uso de los recursos comunicativos que ofrecen las nuevas tecnologías. Desde el pasado siglo, se han vivido grandes cambios que afectan a la técnica y al medio de expresión de la mano del desarrollo mundial de una red de comunicación como es Internet (Cerf, 1993; Navarria, 2016), del nacimiento de la imagen digital (Gómez, 2017) y de la proliferación de nuevos modelos de redes sociales (Ponce, 2012) que irrumpen en la vida cotidiana y en los centros educativos. Luego el potencial de estas herramientas crece de manera exponencial y hoy permite llegar a cualquier rincón del mundo rural, como sucede en este caso, así que la capacidad analítica y crítica del alumnado debe ser prioritaria al tratar una temática tan sensible y se convierte en otro de los propósitos transversales que refuerzan la cohesión del proyecto.

\section{Marco empírico}

Las actividades visuales y plásticas propuestas se estructuran a lo largo de un curso lectivo. Siguen el calendario de las diferentes fechas que marcan la celebración de actos reconocidos a nivel social, que nos sirven de punto de referencia para enlazar todos los ejercicios bajo un mismo común denominador, "la no violencia de género". 


\subsection{Actividad 1}

Se corresponde con el 25N Día internacional para la eliminación de la violencia hacia la mujer. Después de introducir el tema, se plantea la realización de un trabajo por parejas para diseñar diferentes tipos de bocadillos sobre el soporte de cartulinas de color, donde escriben frases e insertan dibujos que expresan su opinión al respecto, todo ello con rotuladores de colores (Fig. 1). Posteriormente, posan con sus respectivos mensajes delante de la puerta de la clase forrada en color violeta, como símbolo de paso hacia la libertad, y se toman fotos para enviar a los medios de comunicación local y comarcal. En esta acción solamente participa el alumnado de $1^{\circ}$ y $2^{\circ}$ ESO.

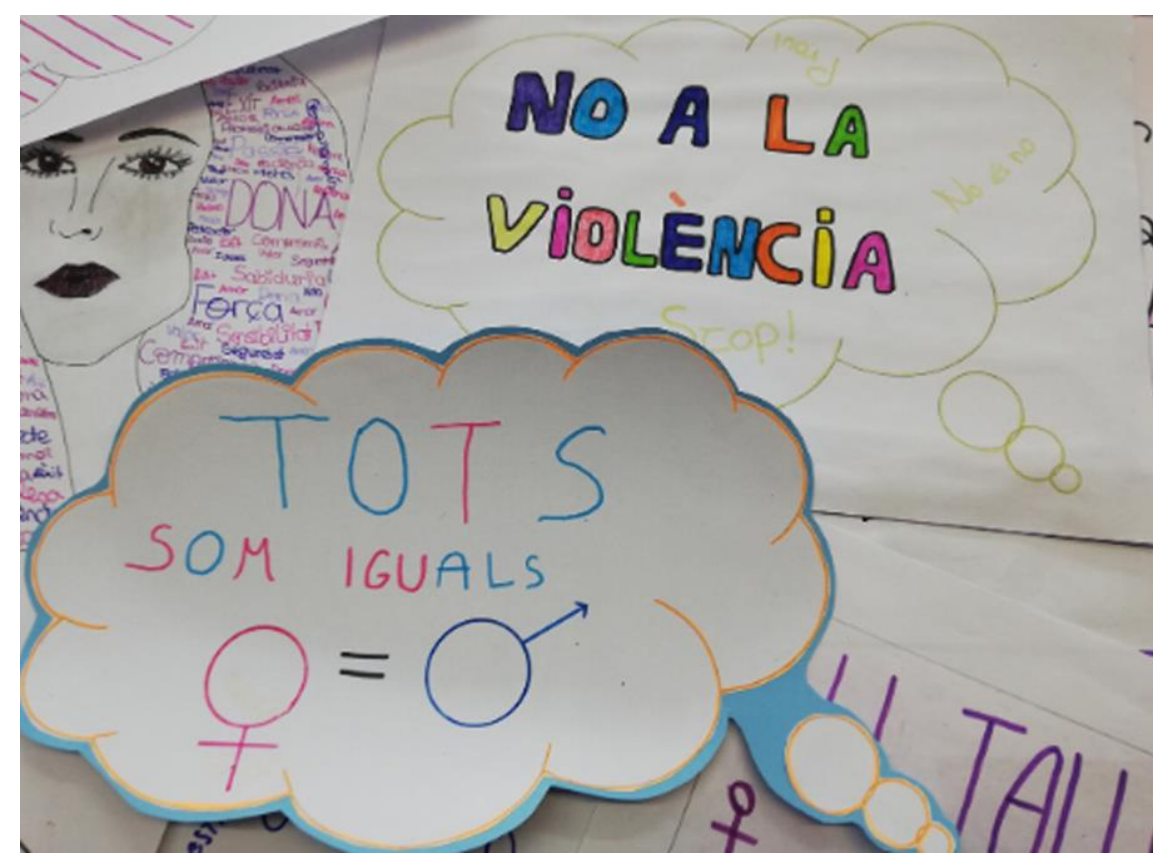

Fig.1 Selección de trabajos realizados por alumnado de $1^{\circ}$ y $2^{\circ}$ ESO para crear un cartel Fuente: Comissió d'imatge de l'institut de Flix

\subsection{Actividad 2}

Se encuadra en la festividad de los Carnavales 2020 y consiste en diseñar, también en parejas, un cartel como punto violeta, pensado para colocar en los lugares designados por la organización del evento a tal fin. En esta ocasión, el alumnado de $1^{\circ}$ y $2^{\circ}$ desarrolla su propuesta sobre una lámina $\mathrm{A} 4$, mientras que se suma el alumnado de $4^{\circ}$ ESO y lo hace en formato A3. En ambos casos ponen en práctica la aplicación de las pinturas acrílicas. Seguidamente, se realiza una selección de los trabajos expuestos para componer una noticia que se remite a los medios de comunicación locales (Fig. 2). 

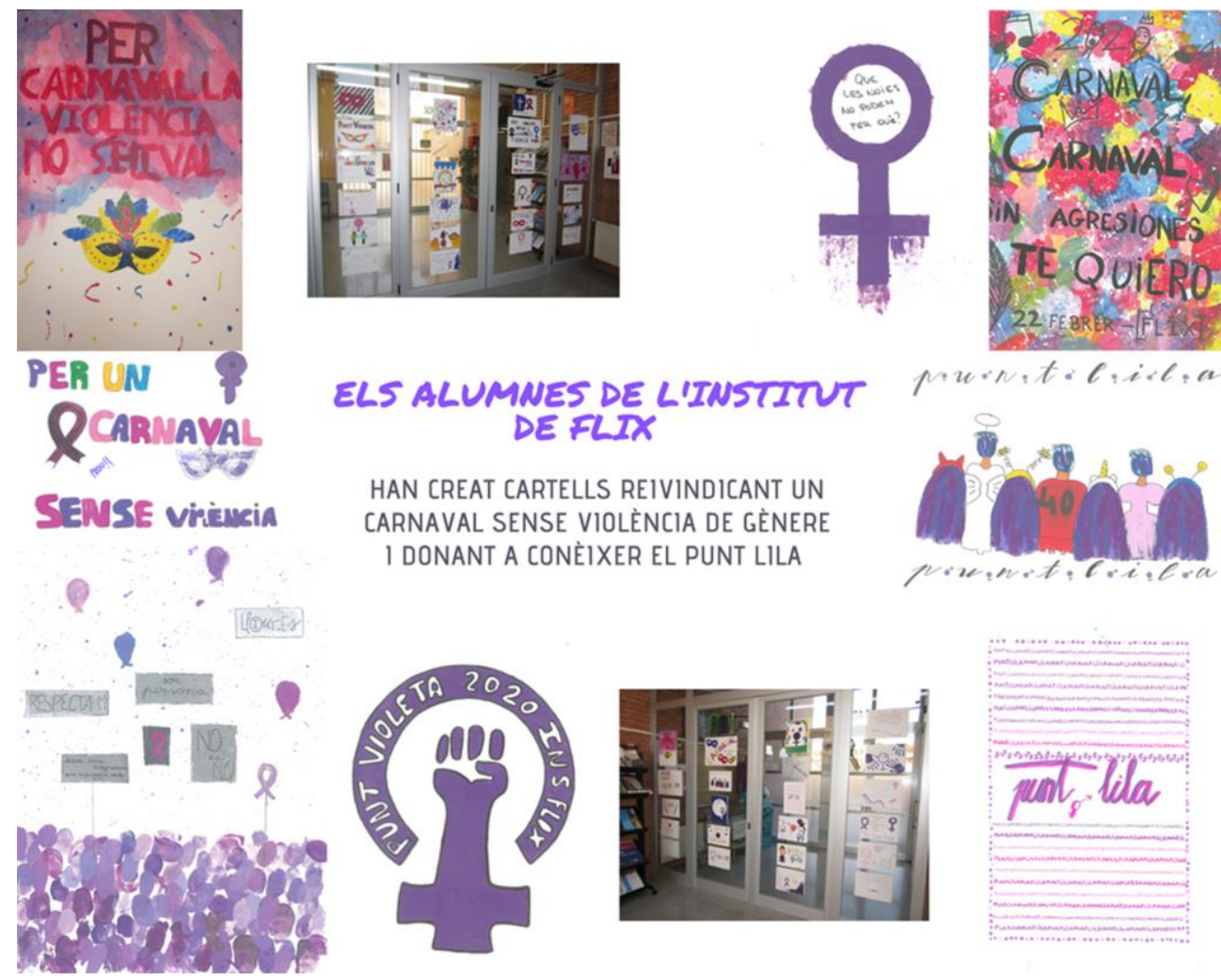

\section{ELS ALUMNES DE LIINSTITUT DE FLIX}

HAN CREAT CARTELLS REIVINDICANT UN CARNAVAL SENSE VIOLĖNCIA DE GĖNERE I DONANT A CONËIXER EL PUNT LILA
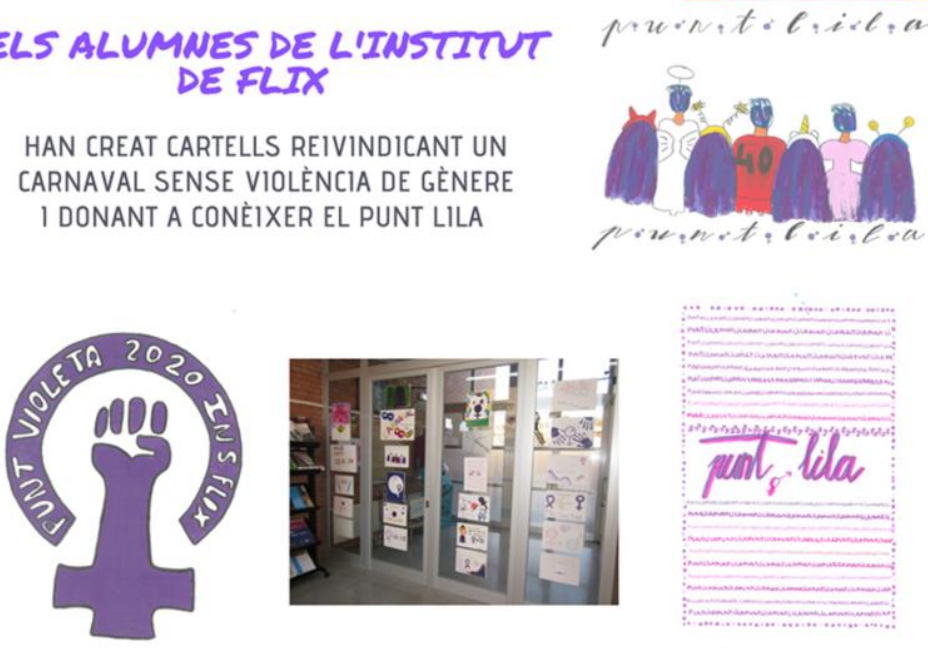

Fig. 2 Noticia con imágenes de los carteles y su exposición a la entrada del centro

Fuente: Comissió d'imatge de l'institut de Flix

\subsection{Actividad 3}

Se contextualiza en torno a la celebración del $8 M$ Día de la mujer trabajadora. Para este ejercicio, entre el alumnado de $4^{\circ}$ ESO se plantea un trabajo grupal, consistente en la creación de una historieta visual tipo cómic con cuatro viñetas que cuenten el devenir de un día cotidiano en la vida de una mujer trabajadora de su tiempo. De nuevo trabajan en formato A3 pero, en este caso, se les concede libertad respecto a la aplicación de las técnicas gráficas y pictóricas (Fig. 3). El último día de la actividad se exponen los trabajos en clase: cada grupo explica su idea en público y, seguidamente, se realiza la coevaluación entre ellos. Resulta muy interesante escuchar sus exposiciones porque clarifican aspectos y detalles que no aparecen explícitos en los dibujos, luego con la palabra enriquecen la imagen y con la imagen ilustran la palabra.

En los grupos de $1^{\circ}$ y $2^{\circ}$ ESO se opta por trabajar de manera individual dentro de las láminas del cuaderno sobre el relato de una mujer del presente que recuerda las vivencias laborales de sus ascendientes y que sueña acerca de su proyección profesional en el futuro. 


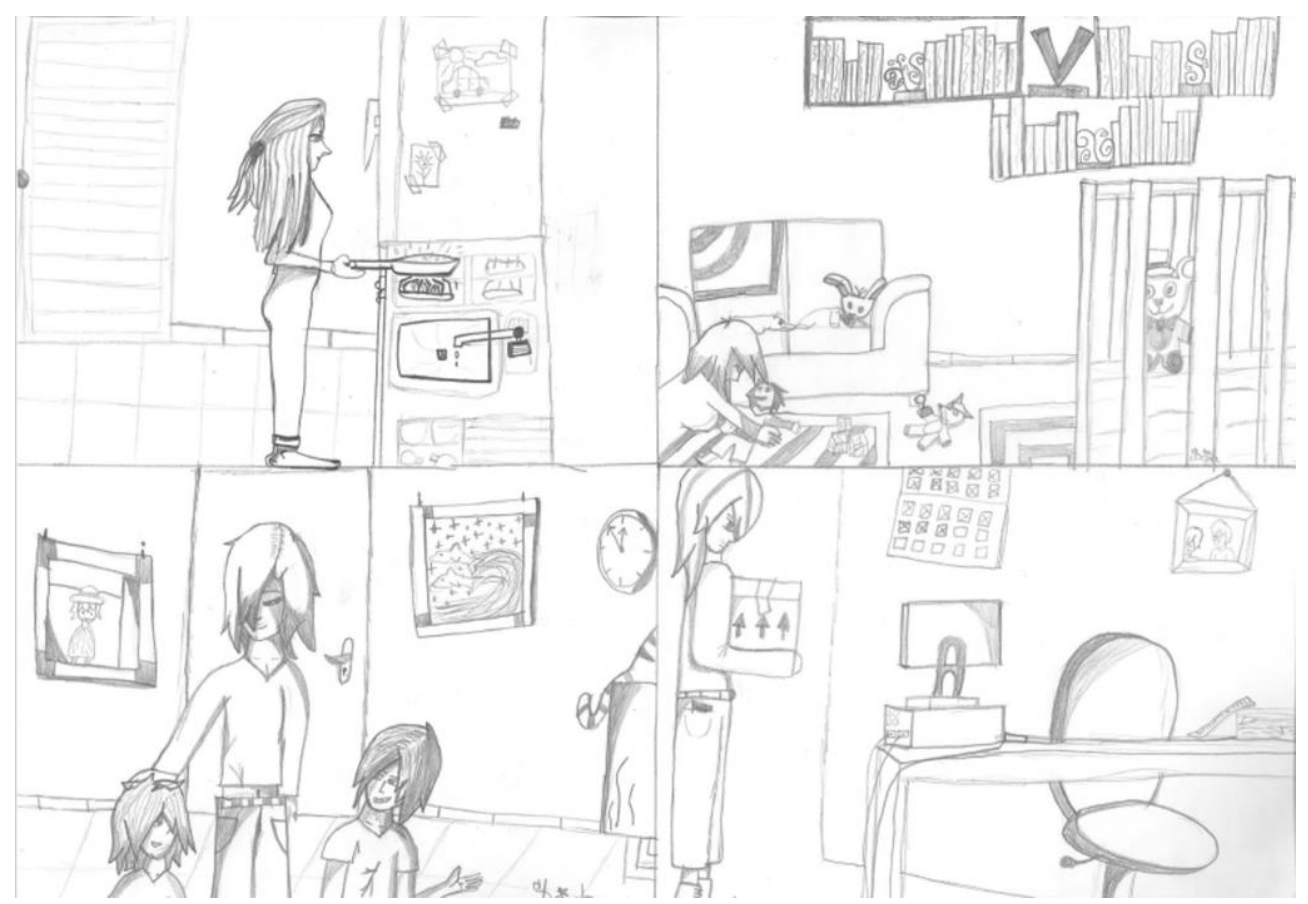

Fig. 3 El día de una mujer trabajadora y su conciliación familiar (gracias a Agda)

Fuente: Grupo de $4^{\circ}$ ESO con alumnado de necesidades especiales

\subsection{Actividad 4}

Inicialmente se prevé la realización de una instalación para decorar varios árboles del patio con motivos florales y pequeños animales e insectos en relación a la llegada de la Primavera y bajo el lema de "Un árbol florido sin violencia de género". Sin embargo, ante la situación de confinamiento, se reformula la actividad y se plantea la traslación de esos motivos decorativos a los balcones, ventanas y terrazas de las casas para compartir esta experiencia con la vecindad pero sin abandonar el fondo reivindicativo sobre el que se crea el trabajo (Fig. 4).

Para esta tarea, se pensaba utilizar gomaeva que tenemos en el centro pero en casa los recursos disponibles son otros, diversos y variados, por lo que se recurre al uso de material de reciclaje, a papel de colores, a cartón de embalaje pintado, a ovillos de lana, a cajas e incluso a latas.

Finalmente, solo participa el alumnado de $2^{\circ}$ y a título individual, aunque en el centro se pensó hacerlo por equipos y extender la participación al alumnado de $4^{\circ}$ que, de hecho, dejó iniciada la actividad pero, con el cierre del centro, no se pudo rescatar el material y allí quedó inacabado. 


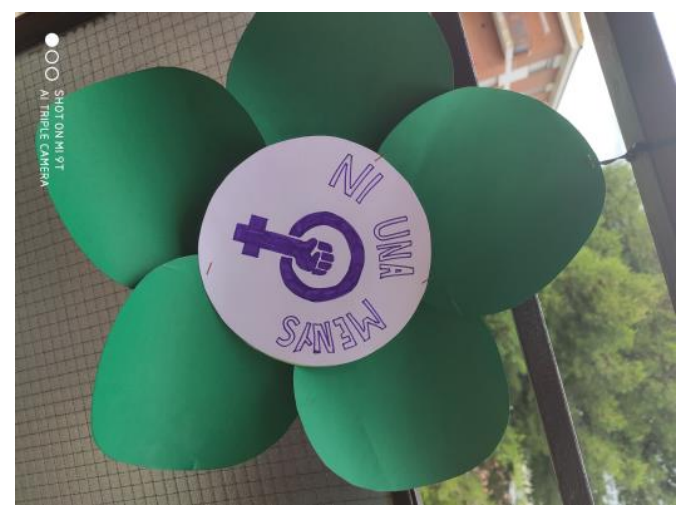

Fig. 4 Motivo floral en el balcón con mensaje en contra de la violencia de género Fuente: Alumno de $2^{\circ}$ ESO

\subsection{Actividad 5}

Gira en torno al Día de la madre y primero se pensó en la elaboración de un pin con fieltro de colores para regalar pero, dada la situación de trabajo en línea y sin el material necesario que quedó en las aulas, se reformula el ejercicio. Se proyecta como tarea de diseño en la que preparan sus esbozos y plantillas, pensando en la ejecución posterior. De nuevo aparecen las alusiones a la mujer y sus reivindicaciones (Fig. 5).

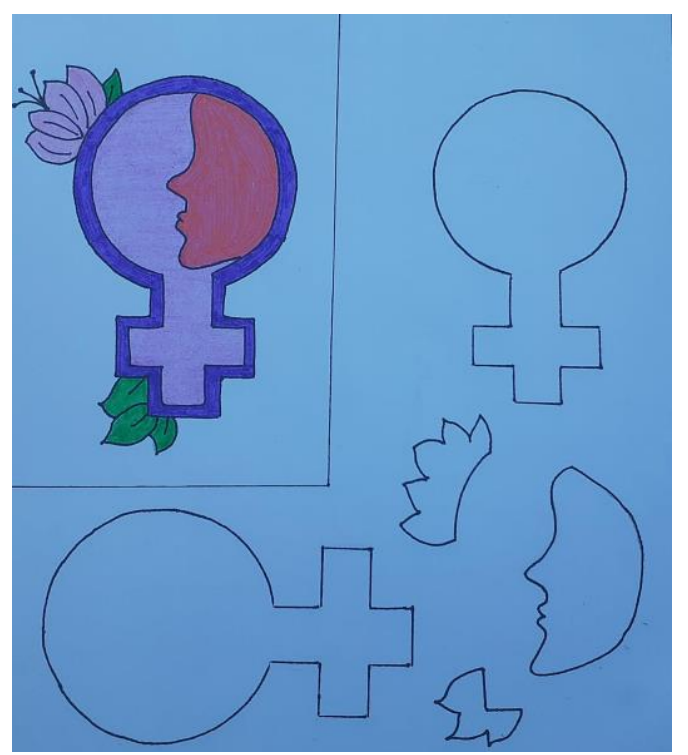

Fig. 5 Diseño de un pin para regalar a la madre Fuente: Alumna de $2^{\circ}$ ESO 


\section{Conclusión}

Se trata de un ejercicio de aproximación al estado de la cuestión que deberá ser tratado por personal especialista en la materia a nivel psicopedagógico y que se espera poder retomar el próximo curso. No obstante, a nivel plástico y desde el punto de vista individual del alumnado, los trabajos han cumplido la función interna de autorreflexión y la externa de comunicación. Por tanto, se estima que los objetivos de partida se han cumplido y cabe seguir con esta labor y coordinar la participación activa entre el alumnado y la ciudadanía en los siguientes cursos.

\section{Referencias}

Ausubel, D.P., Novak, J.D. y Hanesian, H. (1978). Educational psychology: a cognitive view. New York: Holt, Rinehart and Winston.

Cerf, V. (1993). How the Internet came to be. Recuperado de http://www.netvalley.com/archives/mirrors/cerf-how-inet.html

Constitución Española. BOE. Madrid, 29 de diciembre de 1978, núm. 311.

Decret 187/2015, de 25 d'agost, d'ordenació dels ensenyaments de l'educació secundària obligatòria. DOGC. 28 d'agost de 2015, núm. 6945.

Gómez, M. (2017). Historia(s) de la Imagen Digital. Recuperado de https://interartive.org/2017/04/historias-de-la-imagen-digital-marisa-gomez

Institut de Flix (2020). Recuperado de https://iesflix.cat/institut/

Instituto Nacional de Estadística (2019). Nomenclátor: Población del Padrón Continuo por Unidad Poblacional a 1 de enero. Recuperado de http://www.doi.org/mail-archive/reflink/msg00088.html https://www.ine.es/nomen2/index.do?accion=busquedaAvanzada\&entidad_amb=no\&codProv=43 $\& \operatorname{codMuni}=60 \& \operatorname{codEC}=0 \& \operatorname{codES}=0 \& \operatorname{codNUC}=0 \&$ denominacion $\mathrm{op}=$ like \&denominacion $\mathrm{txt}=$ $\underline{\& \mathrm{~L}=0}$

Monleón Pradas, M. (2012). Arte y tecnología frente a la violencia de gènero. Arte y políticas de identidad. Murcia: Servicio de Publicaciones de la Universidad de Murcia. Recuperado de https://revistas.um.es/reapi/article/view/162981

Navarria, G. (2016). How the Internet was born: A stuttered hello. Recuperado de https://theconversation.com/how-the-internet-was-born-a-stuttered-hello-67903

Organización de las Naciones Unidas (1948). Declaración Universal de los Derechos Humanos. París: ONU.Recuperado de https://www.ohchr.org/EN/UDHR/Pages/Language.aspx?LangID=spn

Ponce, I. (2012). Redes sociales. Revista INTEFP. Madrid: Ministerio de Educación, Cultura y Deporte. Recuperado de http://recursostic.educacion.es/observatorio/web/es/internet/web$\underline{\text { 20/1043-redes-sociales?start }=2}$ 